\title{
Rearrangement of stresses in fault zones - detecting major issues of coupled hydraulic-mechanical processes with relevance to geothermal applications
}

\author{
G. Ziefle ${ }^{1, *}$ \\ ${ }^{1}$ Leibniz Institute for Applied Geophysics (LIAG), Stilleweg 2, 30655 Hannover, Germany \\ *now at: Federal Institute for Geosciences and Natural Resources (BGR), Stilleweg 2, 30655 Hannover, \\ Germany
}

Correspondence to: G. Ziefle (gesa.ziefle@ bgr.de)

Received: 8 May 2014 - Revised: 11 July 2014 - Accepted: 24 July 2014 - Published: 10 September 2014

\begin{abstract}
The South German Molasse Basin provides favourable conditions for geothermal plants. Nevertheless, micro-seismic events occur in the vicinity of the geothermal Unterhaching Gt 2 well and seem to be caused by the geothermal plant.

The injection and production are located in an existing fault system. The majority of seismic events takes place at a horizontal distance of $500 \mathrm{~m}$ or less of the borehole. However, none of the seismic events are located in the injection reservoir but in fact at a significantly greater depth. A deeper process understanding of the interacting thermal-hydraulic-mechanical effects in the vicinity of the well is desired.

This article presents a significantly simplified 2-D model, investigating interactions of the stress field in the vicinity of the geothermal well and movements in the fault system. This might be of special interest, as the operation of the geothermal plant might lead to changes in the material and fracture properties on the one hand and in the equilibrium state on the other. A detailed description of the model, as well as various parameter studies, is presented. It can be seen that boundary conditions such as direction of the stress field in relation to the fault system, geometry of the fault system and parameters of the fractures have a significant influence on stresses in the proximity of the geothermal well. A variation in the spatial stress field in some parts of the fault system is to be expected. For the chosen assumptions the dimension of this variation is about $25 \%$ of the assumed stresses. Future work on this model might focus on the characteristics of the fault system, as well as on the influence of the coupled thermal-hydraulic-mechanical effects.
\end{abstract}

\section{Introduction}

The South German Molasse Basin provides favourable conditions for geothermal plants (BStWIVT, 2010). Consequently, about a dozen successfully working geothermal power plants are located in the greater Munich area (Ganz et al., 2013). However, micro-seismic events are observed in the proximity of the geothermal well Unterhaching Gt2 (Megies and Wassermann, 2014). The reason for these events appearing at significantly greater depth than the well - is not yet known. A deeper understanding of the physical processes in this area is of great interest.
Generally, geophysical use of the underground, e.g. deep geothermal energy use, storage of radioactive waste, or the storage of $\mathrm{CO}_{2}$ is characterized by various interacting physical processes. Numerical simulations are a good tool to provide an insight into the thermal-hydraulic-mechanical (THM) coupled processes in the subsurface. General information on the related topics can be found in, for example, Pollard and Fletcher (2005), Zoback (2007), Fossen (2010), and Gudmundsson (2011). Concerning geothermal plants, the injection and production of the water and the variations of temperature have an impact on the mechanical system in the target horizon of the geothermal wells. Taking into account the mechanical and fracture-mechanical effects in the 


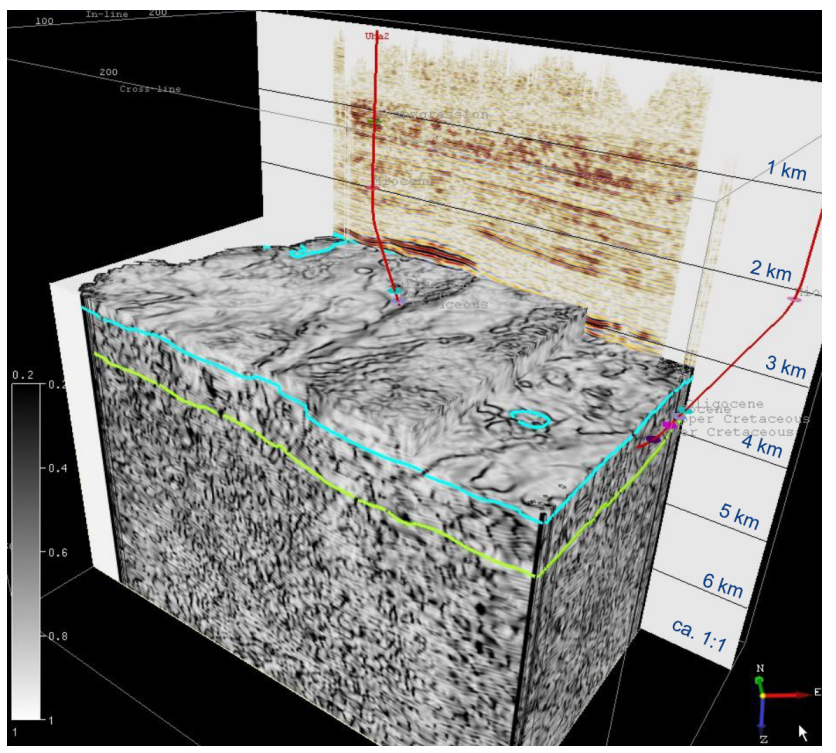

Figure 1. Seismic measurement in the area of the Unterhaching well. Here, the coherence (the similarity between two profiles) is presented. The Unterhaching Gt2 well (left) and the Kirchstockach well (right) are shown in red. The top of the Malm is shown by the blue line, and the bottom by the green line, according to Lüschen et al. (2011) and Lüschen et al. (2014).

deep underground, the existing structures and faults need to be mentioned. Complex, coupled THM problems have to be investigated, aiming for a better process understanding of the evolution of fault zones and their potential impact on seismic events. Utilizing numerical simulation tools to get a better understanding of the relevant effects is a demanding but promising challenge. However, on the one hand, there is a significant lack of information about the system and the specific properties and, on the other hand, the numerical simulation of such complex systems on a large scale is a major challenge even today. In the following, a simplified model approach is presented, focusing on the mechanical effects and the impact of the hydraulic properties in the surroundings of the Unterhaching Gt2 well.

The geological situation of the Unterhaching Gt2 well is given in Fig. 1 based on seismic results. The figure presents the coherence, which indicates fracture or fault zones. The Malm (Upper Jurassic) and the crystalline layer are given as 3-D structures. The Malm is characterized by highly fissured, karstic material. This area is the target horizon of the geothermal wells and is bordered here by the top and bottom lines. The layers above are only indicated by the vertical slice. The Unterhaching and the Kirchstockach wells are shown by red lines. A fault system is located in the near field of the Gt2 well, and will be the focus of the following sections.

Both the well and the seismic events are located close to the fault system, which is presented in Fig. 2 as a schematic view of a vertical slice. The target horizon, namely the Malm,

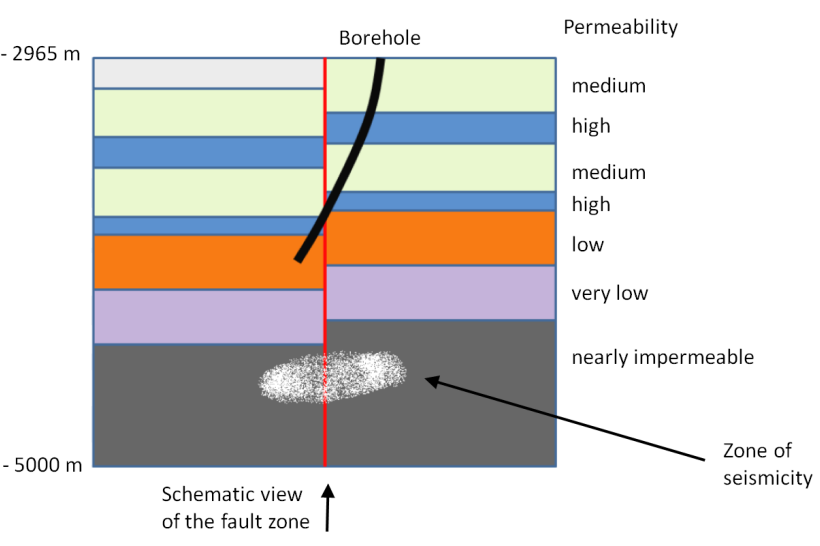

Figure 2. Schematic view of the geological situation in the near field of the Unterhaching geothermal well. Presented are the Malm (multicoloured) and the crystalline layer (in grey) in a vertical slice (after Schumacher, 2013).

is characterized by several layers with different permeabilities. The well intersects the fault zone, which is indicated by the red line. The seismic events are located at a significant distance beneath the well in the crystalline.

\section{Stress field analysis in the area of the geothermal well Unterhaching}

\subsection{Simplification of the model}

The presented geophysical situation implies a threedimensional model with thermal, hydraulic, mechanical and chemical effects. The following investigations concentrate on the mechanical processes and the interaction with some hydraulic effects, which are to be expected in this area. The focus is laid on the stress field in the vicinity of the fault system, which is influenced by elemental movements of the fracture zones. The following investigations give an idea of the impact of these movements - depending on the assumed parameters - on the stress field.

In context of mechanical processes, data describing the fracture-mechanical parameters, as well as information on the stress field and the mechanical parameters in the area of the micro-seismic events, are quite rare. Moreover, the numerical simulation of a three-dimensional geophysical problem incorporating fracture-mechanical processes is not yet possible. However, it is important to get a better understanding of the mechanical processes in and near the fault; therefore, a strictly simplified model is presented in the following section.

The simplification of the model is mainly characterized by the following steps:

\section{2-D instead of 3-D}

Naturally, the effects in the system are threedimensional. However, today few numerical codes exist 
enabling a 3-D numerical simulation of a fully coupled THM problem incorporating fracture mechanics on the required scale. In addition, it is questionable whether such a numerical model would be meaningful due to the lack of input data. Nevertheless, in the simplified twodimensional approach, it is not possible to picture all effects realistically. This simplification is based on the assumption that the main effects can be pictured by the two-dimensional approach and that this model results in a better understanding of the interacting effects.

\section{Downscaling}

A downscaling from the large-scale system to a significantly downscaled model is carried out. The mechanic law of similarity as, for example, presented in Worthoff and Siemes (2012) must be kept in mind. It is applied in the modelling and by interpreting the results. The scale between model and reality is chosen to be $1: 400$.

3. Singular faults instead of fissured areas

In reality, no singular faults are to be expected, as fault zones are characterized by fissured areas with a lateral extent of metres to tens of metres. To model this system it is necessary to reduce the fissured areas to single fracture surfaces due to restrictions of the boundary element (BEM) code FRACOD (Shen, 2002), which is used for this investigation. This simplification has a significant influence on the quantitative results, especially in the proximity of the fault zones. However, the present study focuses on identifying and understanding the dominant mechanical effects - a quantitative statement, though desirable, is beyond the scope of this paper. Nevertheless, even with a qualitative analysis of the results, principal effects can be pictured, future research can be specified and an increase in process understanding can be generated.

The model presented here enables investigations concerning various material parameters of the rock and the fault system. Furthermore, simplification strategies of the fault system, as well as boundary conditions such as stress field and direction of stresses in relation to the fault system, various borehole locations or injection pressures, can be investigated. The varying boundary conditions can describe various phases of the system's evolution and various depths or loading cases. The aim of this model is to increase process understanding and statements regarding the relevance of various input parameters and requirements in further investigations.

\subsection{Model set-up}

The geometry of the fault zones in the vicinity of the geothermal well Unterhaching Gt2 has a significant influence on mechanical and fracture-mechanical effects. To get a better idea of the impact of various properties, the mechanical effects were investigated with FRACOD. A manual for this

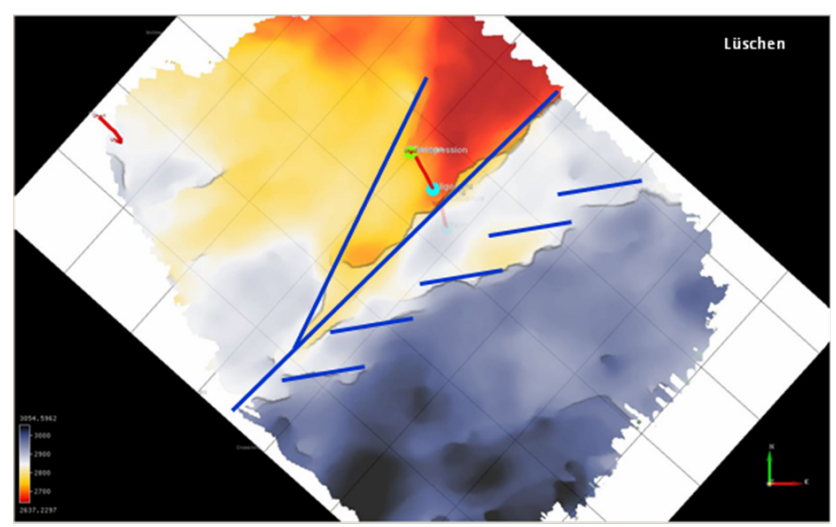

Figure 3. Simplified fault zones (blue lines), injection well (red) and depth of the top Malm horizon (colour coding from red to dark blue indicates from minimum to maximum depth; maximum depth difference $\approx 400 \mathrm{~m}$ ) (Lüschen et al., 2014). Grid line interval is $1 \mathrm{~km}$.

two-dimensional fracture initiation and propagation code is presented in Shen and Stephansson (1993b). Further information on this topic is given in Byerlee (1978), Ferrill and Morris (2003), Rinne (2008) and Shen et al. (2014). FRACOD utilizes the displacement discontinuity method (DDM) in combination with the Mohr-Coulomb failure criterion and a new fracture criterion ( $\mathrm{G}$ criterion) proposed by Shen and Stephansson (1993a). FRACOD is designed to capture fundamental features of the fully coupled hydro-mechanical behaviour of elastic and isotropic rocks.

\subsubsection{Geometry}

Taking into account the seismic results given in Fig. 1, a significantly simplified model of the geometry of the fault zones is developed. Figure 3 depicts the depth to the top of the Malm and the simplified geometry of the fault zones in the simplified model.

The area given in Fig. 3 has an extension of about $8.0 \mathrm{~km} \times 5.5 \mathrm{~km}$. The zone of interest lies in the centre of the presented area and consists of the main fault (presenting the fault zone with an angle of about $45^{\circ}$ ), the minor fault (representing the fault zone with an angle of about $20^{\circ}$ ) and the en echelon fault system. The geometry of the downscaled model is depicted in Fig. 4. Due to the downscaling process (a factor of 1 / 400), the model area has an extension of $12 \mathrm{~m} \times 12 \mathrm{~m}$ and depicts the zone of interest in the vicinity of the fault system.

\subsubsection{Material properties}

The material parameters can be split into material properties of rock and water and properties of the fractures. These are summarized in Table 1 for a so-called standard model, which will be the basis for all parameter studies. Some of 


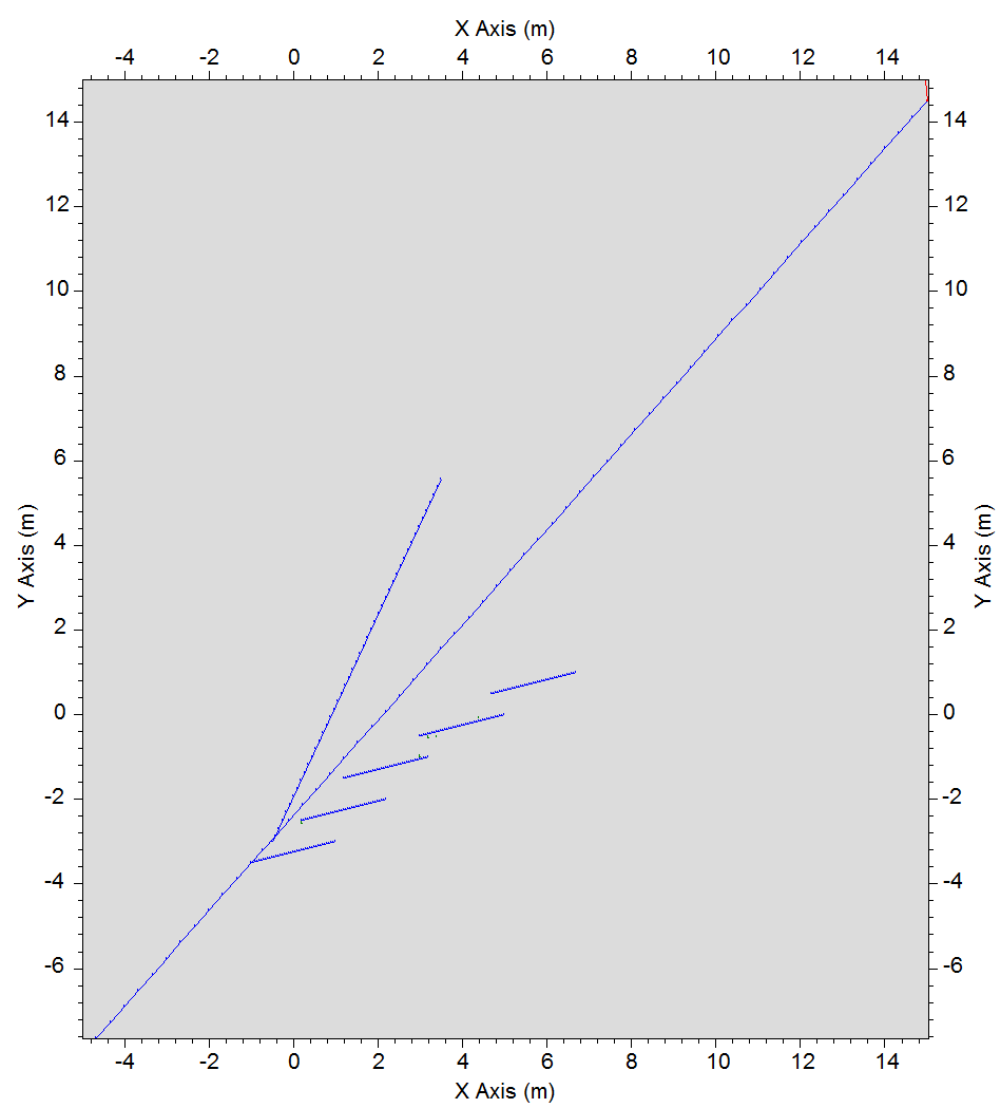

Figure 4. Significantly simplified geometry of the downscaled model of the fault zones in the area of the Unterhaching Gt2 geothermal well.

these parameters will be varied later for the purpose of parameter studies. The material parameters are calibrated based on information taken from Gehle (2002), Mattle et al. (2003), Rinne et al. (2003) and Moeck and Backers (2011). The calibration is carried out under the assumption that the system of fault zones is nearly under equilibrium conditions. Finally, it can be pointed out that the model is very sensitive to numerous parameters.

\subsubsection{Simulation of the standard model}

The model area is loaded by a complex stress field consisting of compressive and shear stresses. Simplifying this, the boundary conditions in the model are related to the major and minor horizontal stresses, which results in an anisotropic compressive stress field. The direction of stresses in this area is taken from Reinecker et al. (2010). Based on results taken from Gehle (2002), they are assumed to be $120 \mathrm{MPa}$ in the north-south direction and $60 \mathrm{MPa}$ in the east-west direction. As the model is oriented north, the mean stresses are parallel to the $y$ axis.

The resulting elastic displacements along the fault zones are shown in Fig. 5 (left). Converted to realistic values according to the scaling assumption presented in Sect. 2.1, these values are in the range of centimetres. More precisely, the values vary between 2 and $22 \mathrm{~cm}$, with lower values in the en echelon system and maximums in the main fault. Lastly, there exists a relative displacement along the main fault. While the area located in the NW of the main fault moves in the south-western direction, the area located in the $\mathrm{SE}$ of the main fault moves in the NE direction. The fault displacements in the minor fault and in the system of en echelon faults are significantly smaller than in the main fault.

Figure 5 (right) presents the deformations of the rock. The scale used is equal to that of the displacements along the faults given in Fig. 5 (left). The induced stresses result in deformations of the order of decimetres. Due to the dynamic in the system, some areas experience lower (blue) or higher (red) deformations.

The resulting mean stresses are given in Fig. 6. The green areas correspond to the initial compressive stress of $120 \mathrm{MPa}$. In the red areas a decrease in the initial compressive stress takes place. Here, the compressive stresses are reduced due to a redistribution of stresses in the model area. The area close to the en echelon system in particular is characterized by a decrease in the compressive stresses. In contrast to that, the blue areas mark regions with an increased compressive stress. As might be expected, stress peaks arise at the ends of the singular faults. Here, fracture processes are 
Table 1. Material parameters of the standard case necessary for the FRACOD model

\begin{tabular}{lllr}
\hline Parameter & Symbol & Unit & Value \\
\hline Rock & & & \\
\hline Young's modulus & $E$ & GPa & 50 \\
Poisson's ratio & $v$ & - & 0.35 \\
Friction angle & $\phi$ & $\circ$ & 30 \\
Cohesion & $c$ & $\mathrm{MPa}$ & 0.25 \\
Tensile strength & $\sigma_{Z}$ & $\mathrm{MPa}$ & 12.1 \\
Mode I fracture toughness & $K_{\mathrm{IC}}$ & $\mathrm{MPa} \mathrm{m}^{0.5}$ & 1.3 \\
Mode II fracture toughness & $K_{\mathrm{IIC}}$ & $\mathrm{MPa} \mathrm{m}^{0.5}$ & 5.29 \\
\hline Fractures & & & \\
\hline Shear stiffness & $K_{\mathrm{S}}$ & $\mathrm{GPa} \mathrm{m}{ }^{-1}$ & 20 \\
Normal stiffness & $K_{\mathrm{n}}$ & $\mathrm{GPa} \mathrm{m}^{-1}$ & 40 \\
Friction angle & $\phi$ & $\circ$ & 20 \\
Cohesion & $c$ & $\mathrm{MPa}$ & 1 \\
Cut-off level of fracture propagation & $f$ & - & 0.995 \\
Check-up level for elastic fracture growth & $e$ & - & 0.0 \\
Tolerance factor & $t$ & - & 1.0 \\
\hline Hydraulic parameter & & & \\
\hline Bulk modulus of the fluid & $K_{\mathrm{w}}$ & $\mathrm{GPa}$ & 2.0 \\
Permeability & $k$ & $\mathrm{~m}^{2}$ & $1 \times 10^{-19}$ \\
Viscosity & $\mu$ & Pa s & $1 \times 10^{-3}$ \\
\hline
\end{tabular}
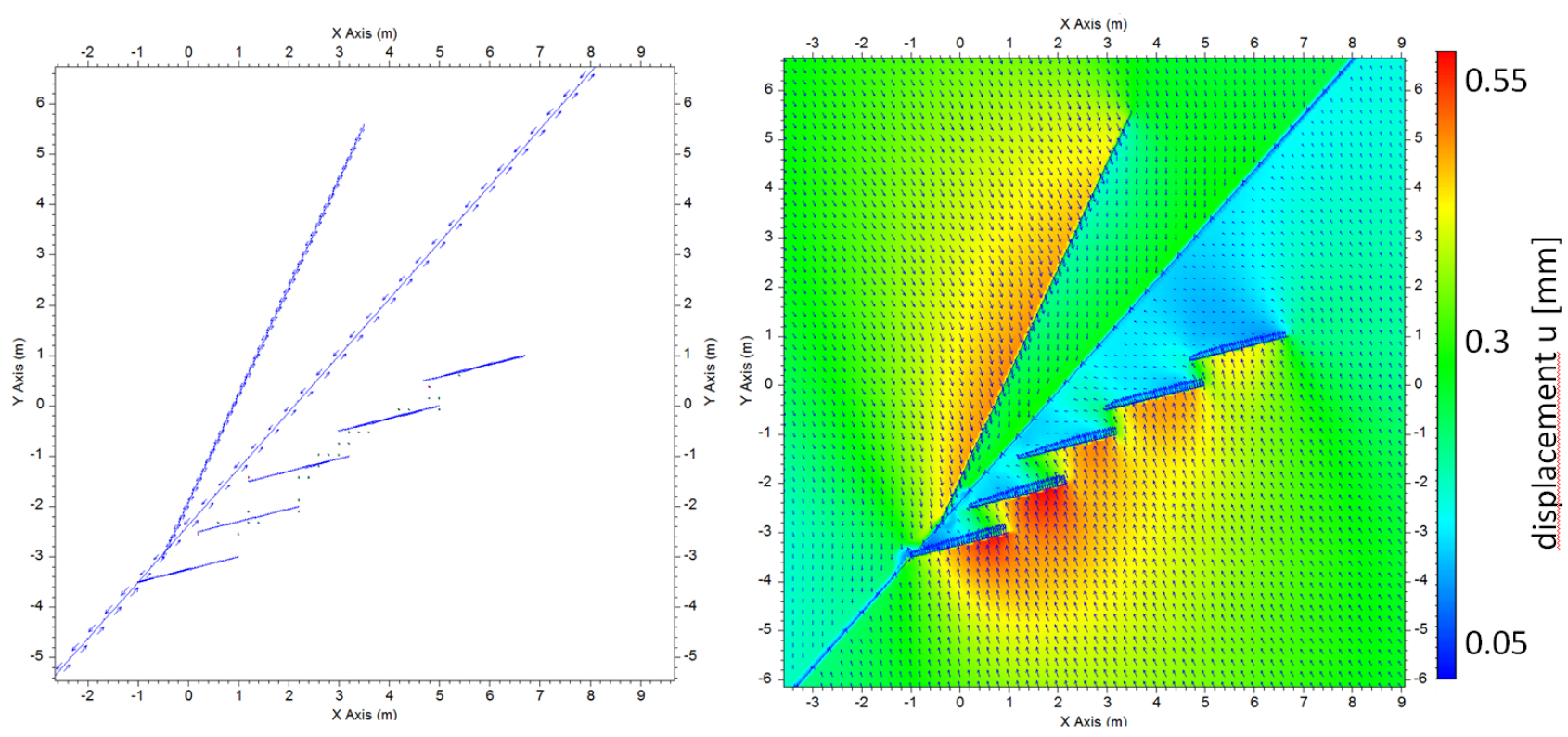

Figure 5. Displacements in the standard model due to the stress field applied (left: in the faults; right: in the rock). Converted to realistic values according to the assumptions in Sect. 2, the values are in the range of a few centimetres.

to be expected. However, these extreme changes in the stress field at the end of the faults do not fit well with reality - in actual fact they will be smaller because the existence of fissured areas instead of singular faults will dampen the changes.
Finally, it can be stated that a movement along the main fault can be observed due to the assumed boundary conditions and material parameters. This results in an area of reduced compressive stresses in the vicinity of the en echelon faults. This assumption coincides with the interpretation 

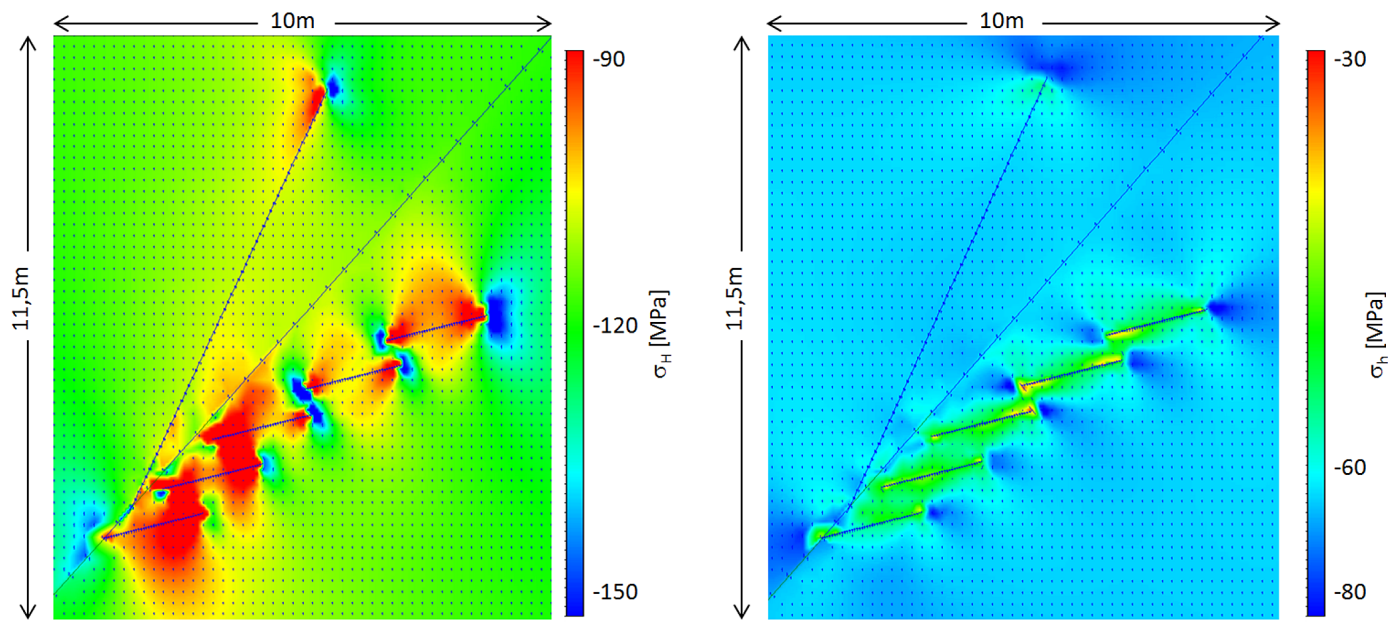

Figure 6. Variation in the major (left) and minor (right) stresses. In some areas of the fault system, variations of about $25 \%$ can be observed in the large-scale stress field.
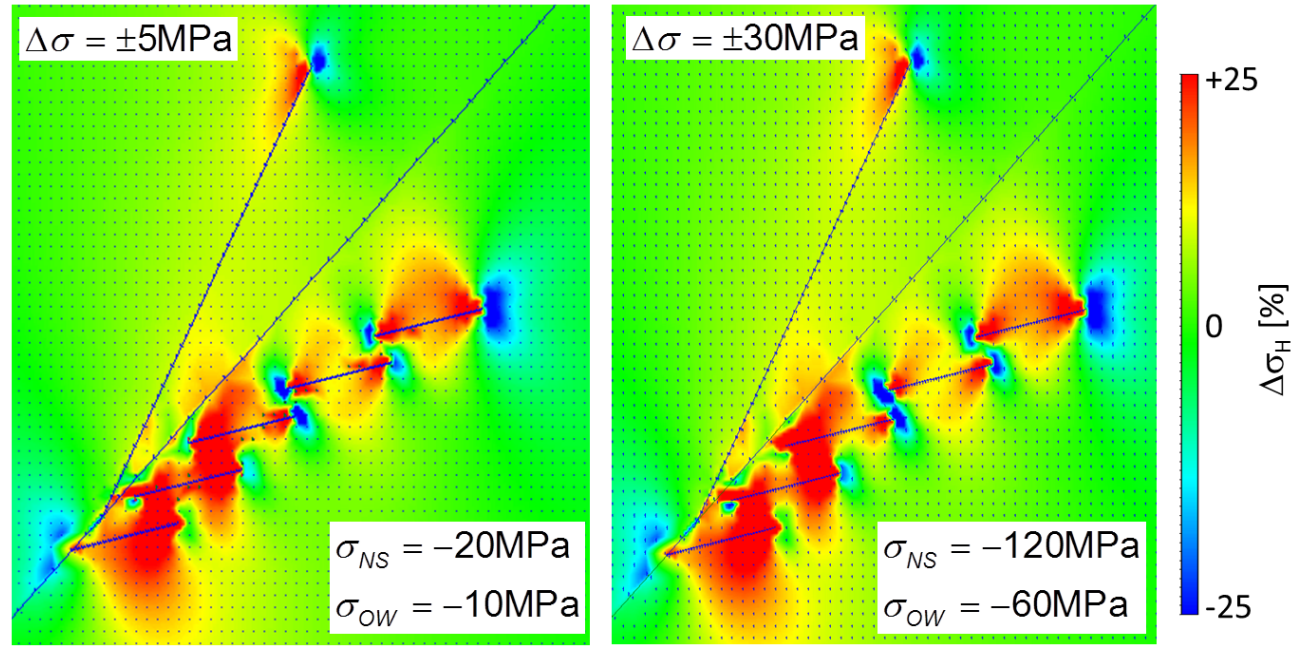

Figure 7. The variation in stresses in the near field of the fault system ranges by about $25 \%$. This relation is independent of the magnitude of the stress field.

based on the seismic measurements, which indicate areas of higher (in the vicinity of the minor fault) and lower (in the vicinity of the en echelon system) compressive stresses.

However, the presented stress field strongly depends on the boundary conditions of the system. Consequently, the influence of the stress field, as well as the material properties, will be investigated in the following sections. Some investigations concerning the influence of the borehole location are presented in Ziefle (2013). Depending on the depth, the location of the well changes with regard to the fault system. This might be of significant interest and could be a focus for further numerical investigations.

\subsubsection{Influence of the stress field}

The stress field in the Molasse Basin is discussed in Reinecker et al. (2010). It is assumed to be oriented in a N-S direction. Quantitative data are given by Seithel (2013). This information results from the investigation of borehole breakouts.

In this section the standard model, loaded with a stress field of $120 \mathrm{MPa}$ in the $\mathrm{N}-\mathrm{S}$ direction and $60 \mathrm{MPa}$ in $\mathrm{E}-\mathrm{W}$ direction, is compared with a similar model, loaded only by $20 \mathrm{MPa}$ in the $\mathrm{N}-\mathrm{S}$ direction and $10 \mathrm{MPa}$ in $\mathrm{E}-\mathrm{W}$ direction. The results are given in Fig. 7. The initial mean stress and the variation in the stress up to a level of $25 \%$ are presented. It becomes clear that the initial value of 120 or $20 \mathrm{MPa}$ remains constant in the far field (shown in green) while changes can be observed in the vicinity of the fault system. As expected, 

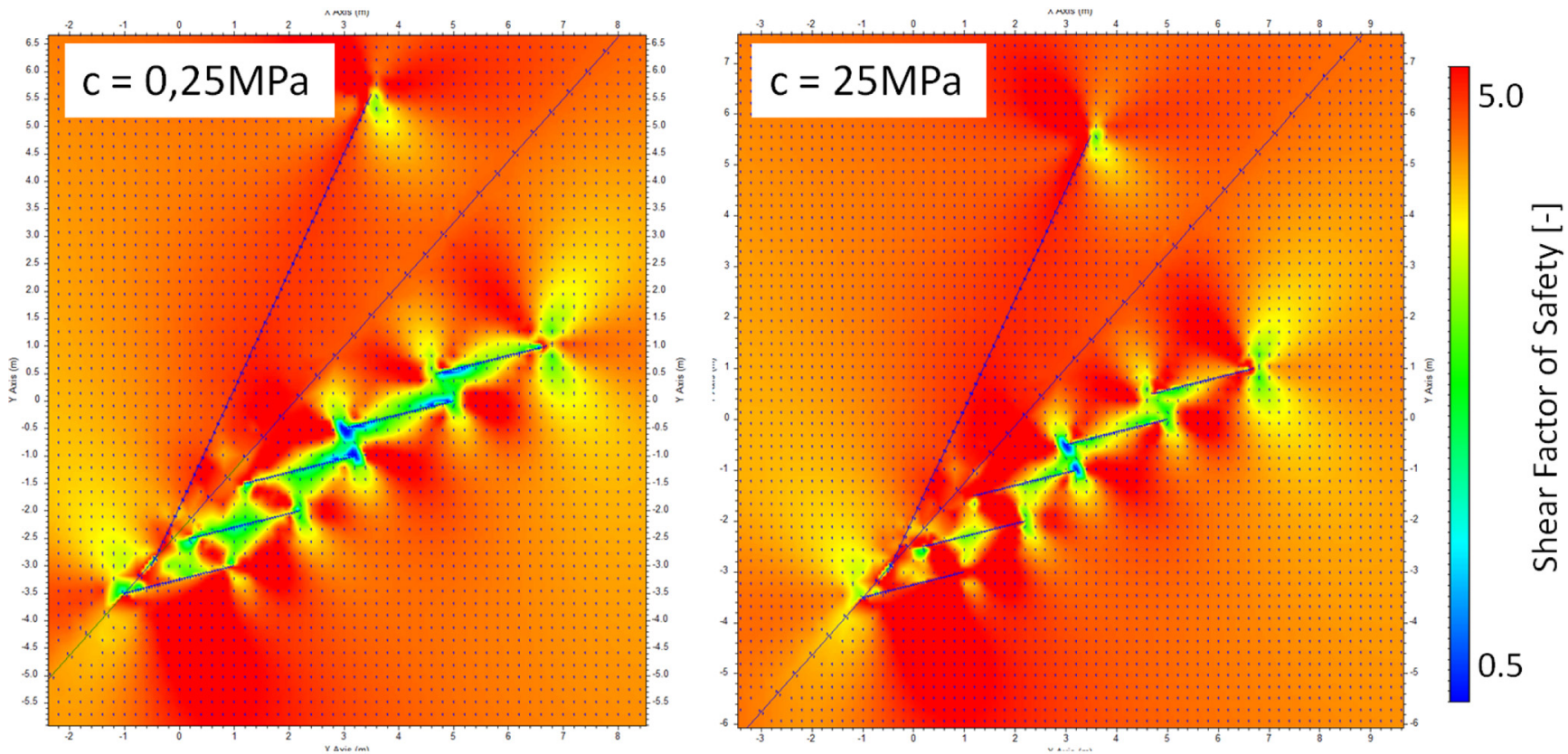

Figure 8. The variation in the cohesion has a moderate influence on the stress field. Pictured here is the safety factor depending on the relation of shear stress and shear stiffness.

the compressive stresses increase at the end points of the assumed singular faults (shown in blue). Moreover, a trend of a decreased compression field in the vicinity of the en echelon system is detected (shown in red). The variation in the stress reaches a level of about $25 \%$. Due to the difference in the initial stress, this variation has a value of $30 \mathrm{MPa}$ in the standard case and a value of $5 \mathrm{MPa}$ in the second case.

Finally, it can be stated that the variation in stresses for both cases remains, as a percentage, of the same order of magnitude. In the vicinity of the faults, variations of about $25 \%$ related to the initial stress field have to be expected.

\subsubsection{Influence of the material properties}

The material properties consist of properties of the rock and the faults. Due to the significant simplification of the fissured areas as singular faults, the definition of fault properties is problematic. Parameter studies indicate a strong influence of fault properties on the results, while the influence of the material properties is comparatively low. In this section, the impact of some properties is summarized.

Figure 8 presents a comparison of two models with varying properties for the cohesion of the rock. While the assumed cohesion in the standard case remains $0.25 \mathrm{MPa}$, the comparative case is characterized by a cohesion of $25 \mathrm{MPa}$. Presented in the Fig. 8 is the safety factor, which depends on the relation of shear stress and shear stiffness. The results indicate a moderate influence of the cohesion.
The stresses which result from a variation in the friction angle of the rock are given in Fig. 9. A friction angle of $15^{\circ}$ does not lead to a significant change in the results compared with the initial value of $30^{\circ}$.

Regarding the presented model set-up without any injection, production or changes of boundary conditions, there is no difference between a pure mechanical and a coupled hydraulic-mechanical approach. This is also presented in Fig. 9. Here, the simulation results on the left-hand side arise from a pure mechanical calculation while the results on the right side arise from a coupled hydraulic-mechanical simulation. The coupled simulation is characterized by faults, which are filled with water.

The fault is characterized by various parameters given in Table 1. A variation in the friction angle of the fault has a significant influence on the stress field. A shift of the initial value of $20^{\circ}$ to a value of $10^{\circ}$ leads to the results presented in Fig. 10. Due to the dynamic effects in the system, the resulting stress field varies enormously.

Another significant parameter of the faults is their stiffness. Considering the behaviour of fault systems in context with geothermal applications, this parameter is of special interest. Due to the injection or production of a fluid, the characteristics of the fault zones and the stress and fluid pressure conditions in the fault may change (e.g. Morris et al., 1996; Hillis, 2000; Legarth et al., 2005). By analysing the stiffness of faults and how the system reacts to variations of this parameter, a first insight into this complex interaction can be gained. 

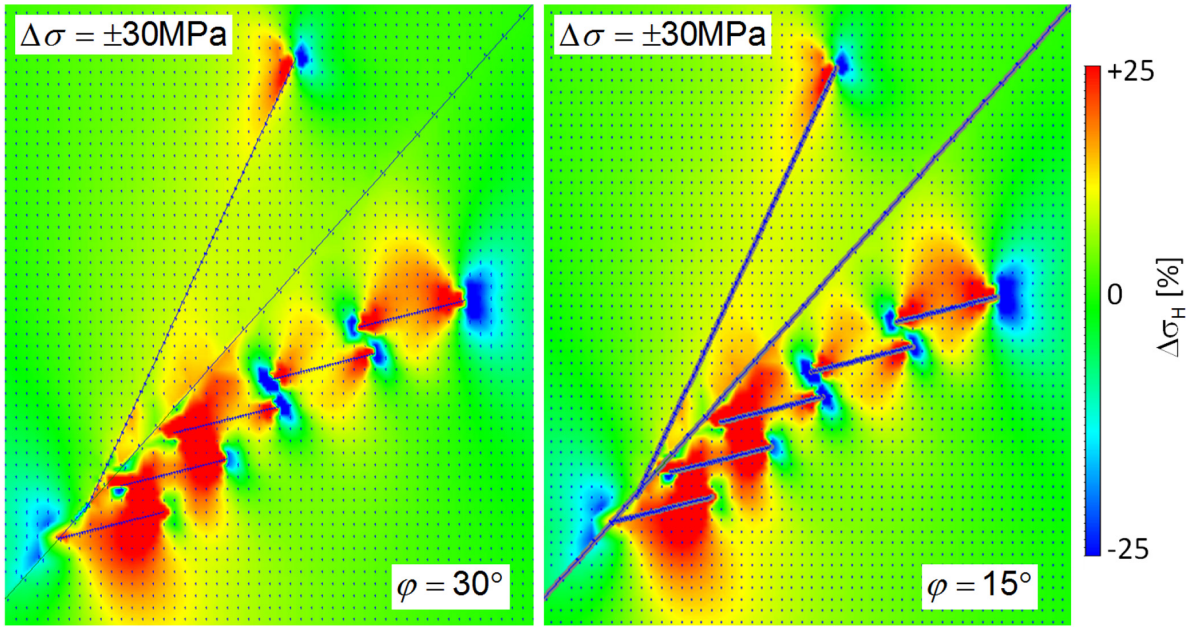

Figure 9. Stress field in the vicinity of the fault system. The variation of the friction angle of the rock has essentially no influence on the stress field.
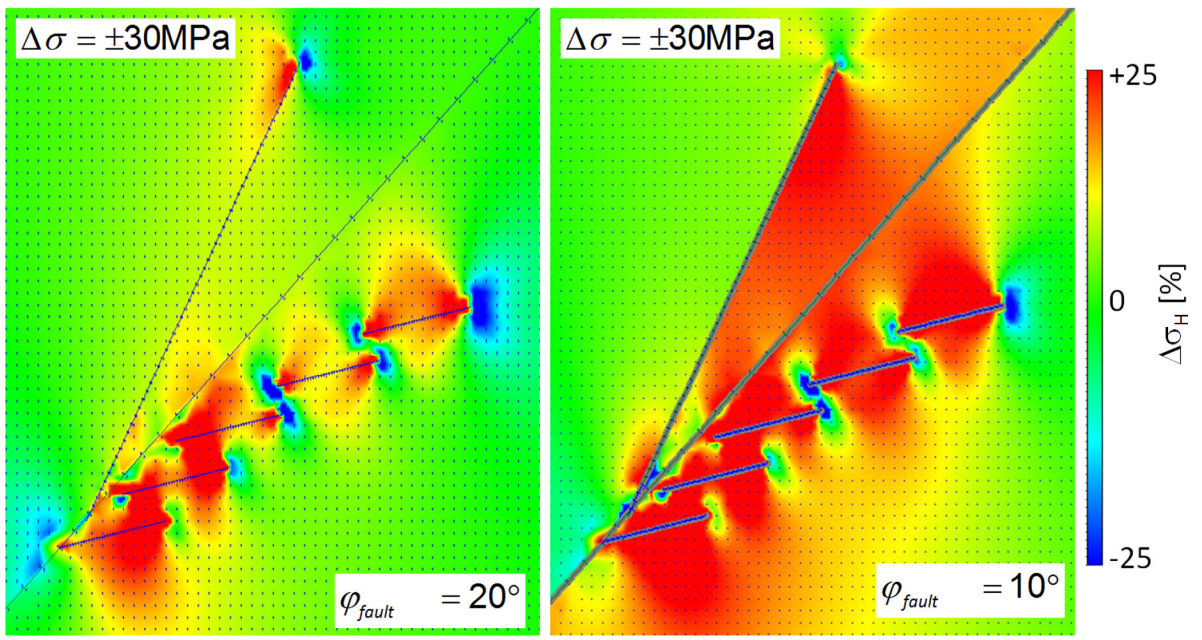

Figure 10. Due to the variation in the friction angle of the fault zones, the remaining stress field varies significantly. The area with a significant change in the stress field compared to the initial one is considerably higher due to the lower friction angle of $10^{\circ}$.

Starting with an assumed shear stiffness of $20 \mathrm{GPa}$ and normal stiffness of $40 \mathrm{GPa}$, a decrease in both values by $75 \%$ is assumed to occur only in the main fault. This change already has a significant influence on the stress field. This can be seen by comparing Fig. 7 (right) with Fig. 11 (left). Additionally, with the assumption of the same decrease in stiffness for the minor fault, the resulting stresses are shown in Fig. 7 (right). The impact of these changes can be seen immediately - the area which is characterized by a significant decrease in the compressive stresses becomes larger. As a consequence, the equilibrium of forces in the vicinity of the fault system may change.

Nevertheless, these investigations are only a very rough approach to examine the effects within the fault system and their influence on the overall stress field. The key findings of the presented work are shown in Fig. 12. Here, the re- sulting stress field is presented in combination with the seismic data. Future work might incorporate coupled hydraulicmechanical effects more precisely. For example, the consideration of the pore pressure in the faults and changes in fault properties such as the aperture of the fault might be of special interest. Furthermore, a detailed investigation of local parameter variations could yield new insights into interactions between faults.

\section{Conclusions}

A significantly simplified 2-D model depicting the fault system in the vicinity of the geothermal well Unterhaching Gt2 is presented. Calibration is carried out in order to achieve a mechanical situation which is very close to the equilibrium state, as this corresponds best to the current state of 

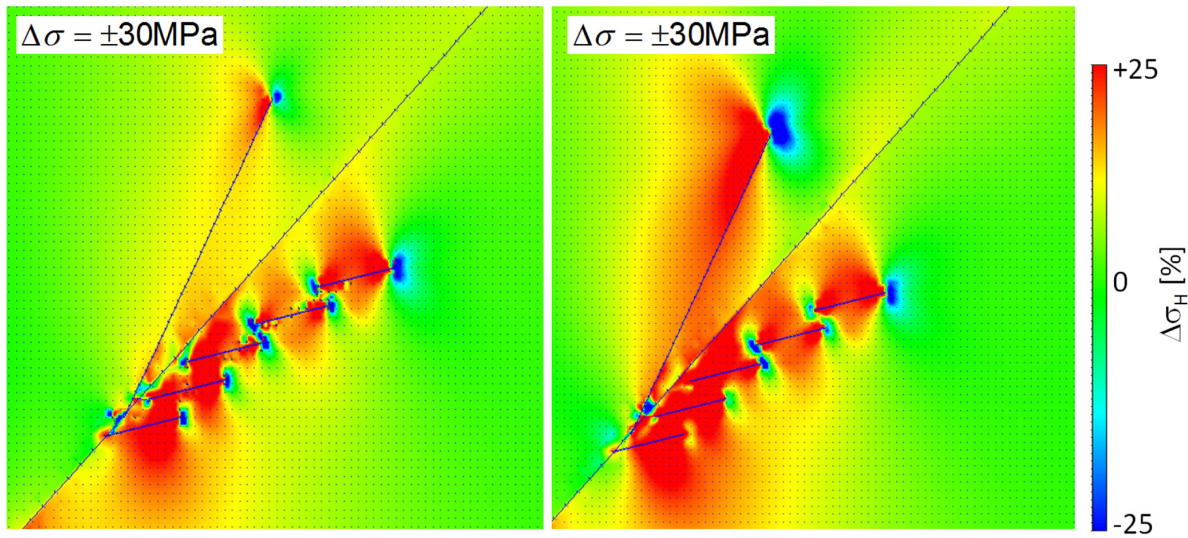

Figure 11. Stresses due to the assumption of a decrease in stiffness by $75 \%$ for the main fault only (left) and for the main and the minor fault (right).

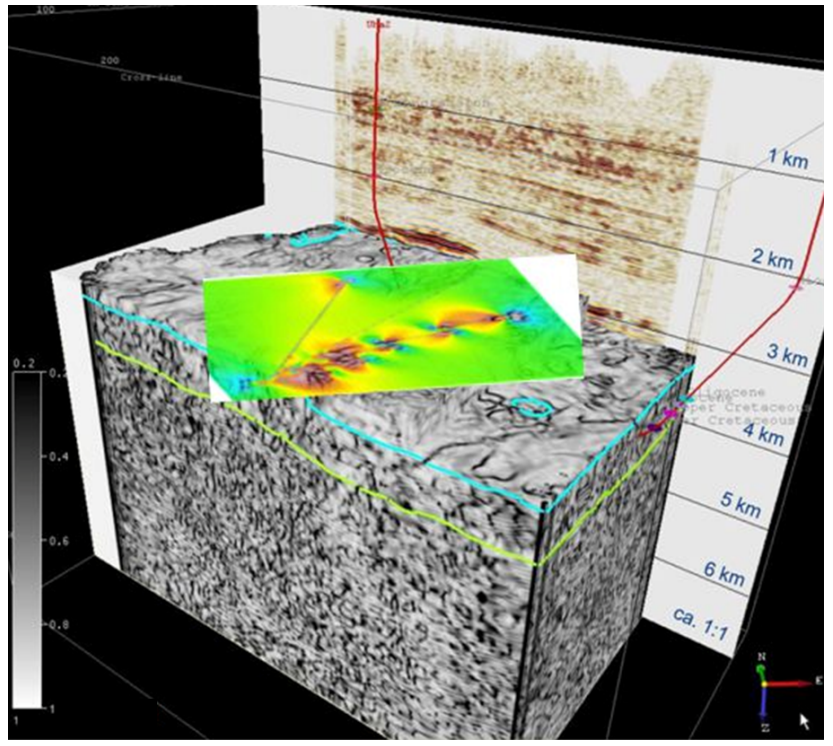

Figure 12. Seismic data in the area of the Unterhaching well (as given in Fig. 1) combined with the stress field derived by the numerical simulation. The areas shown in green correspond to the initial compressive stress field. However, different colours indicate changes in the stress field compared to the spacial stresses.

the system in reality. The presented investigations imply various parameter studies and focus on the impact of minimal movements in the fault system on the stress field. The aim of this model is a better process understanding and better classification of the significant material properties. With this, it is possible to better develop future investigations of coupled thermal-hydraulic-mechanical processes.

The numerical model indicates a relative movement along the main fault. This movement leads to a pressure decrease around the en echelon structures. For the chosen model setup, the range of all changes in the stress field can be given by approximately $25 \%$ of the initially assumed stresses. Fur- ther investigations focus on the impact of various boundary conditions and material parameters. It is necessary to point out that the material properties of the assumed fractures have a significant influence on the movements in the system and consequently on the resulting stress field. In contrast, the material properties of the rock have only a moderate influence. Testing the influence of the initial stress field indicates only a quantitative influence. Higher initially assumed stresses result in higher stresses in the fault system, but the qualitative arrangement remains the same.

Further investigations may focus on the impact of coupled hydraulic-mechanical processes. The influence of the injection on the properties of the fault system will be of special interest. Furthermore, 3-D investigations can incorporate the influence of the non-vertical well and the injection and production of the fluid.

Acknowledgements. I would like to express my thanks to the Leibniz Institute for Applied Geophysics (LIAG) for the kind support. The work presented in this paper was financed in the context of a reintegration programme after parental leave.

Edited by: W. Freeden

Reviewed by: H. Rüter and one anonymous referee

\section{References}

BStWIVT - Bayerisches Staatsministerium für Wirtschaft, Infrastruktur, Verkehr und Technologie: Bayerischer Geothermieatlas - Hydrothermale Energiegewinnung, 93 pp., München, 2010.

Byerlee, J. D.: Friction of rocks, Pure Appl. Geophys., 116, 615626, 1978.

Ferrill, D. A. and Morris, A. P.: Dilational normal faults, J. Struct. Geol., 25, 183-196, 2003.

Fossen, H.: Structural Geology. Cambridge University Press, Cambridge, 2010. 
Ganz, B., Schellschmidt, R., Schulz, R., and Sanner, B.: Geothermal Energy Use in Germany - Proceedings European Geothermal Congress 2013, 16 pp., Pisa, Italy, 3-7 June 2013.

Gehle, C.: Bruch- und Scherverhalten von Gesteinstrenn- flächen mit dazwischenliegenden Materialbrücken. Schriftenreihe des Institutes für Grundbau und Bodenmechanik der RuhrUniversität Bochum, 33, 1439-9342, Bochum 2002.

Gudmundsson, A.: Rock Fractures in Geological Processes, Cambridge University Press, Cambridge, 2011.

Hillis, R.: Pore pressure/stress coupling and its implications for seismicity, Explor. Geophys., 31, 448-454, 2000.

Legarth, B., Huenges, E., and Zimmermann, G.: Hydraulic fracturing in sedimentary geothermal reservoirs, Int. J. Rock Mech. Min., 42, 1028-1041, 2005.

Lüschen, E., Dussel, M., Thomas, R., and Schulz, R.: 3D seismic survey for geothermal exploration at Unterhaching, Munich, Germany, First Break, 29, 45-54, 2011.

Lüschen, E., Wolfgramm, M., Fritzer, T., Dussel, M., Thomas, R., and Schulz, R.: 3D seismic survey explores geothermal targets for reservoir characterization at Unterhaching, Munich, Germany, Geothermics, 50, 167-179, 2014.

Mattle, B., John, M., and Spiegl, A.: Numerische Untersuchungen für den Tunnelbau im verkarsteten Gebirge, Felsbau, Rock and Soil Engineering, 21, 29-34, Verlag Glückauf, 2003.

Megies, T. and Wassermann, J.: Microseismicity observed at a non-pressure-stimulated geothermal power plant, Geothermics, in press, doi:10.1016/j.geothermics.2014.01.002, 2014.

Moeck, I. and Backers, T.: Fault reactivation potential as a critical factor during reservoir stimulation, First Break, 29, 73-80, 2011.

Morris, A., Ferrill, D. A., and Henderson, D. B.: Slip tendency analysis and fault reactivation, Geology, 24, 275-278, 1996.

Pollard, D. D. and Fletcher, R. C.: Fundamentals of Structural Geology, Cambridge University Press, Cambridge, 2005.

Reinecker, J., Tingay, M., Müller, B., and Heidbach, O.: Presentday stress orientation in the Molasse Basin, Tectonophysics, 482, 129-138, 2010.

Rinne, M.: Fracture Mechanics and Subcritical Crack Growth Approach to Model Time-Dependent Failure in Brittle Rock. Dissertation, ISBN 978-951-22-9435-0, Helsinki University of Technology, 2008.
Rinne, M., Shen, B., and Lee, H.-S.: Äspö Hard Rock Laboratory, Äspö Pillar Stability Experiment, Modelling of fracture stability by Fracod - Preliminary results. International Progress Report IPR-03-05, Fracom, 2003.

Schumacher, S.: Induzierte Seismizität: Ursachenforschung durch numerische Modellierung am Beispiel Uha Gt2. Der Geothermie Kongress DGK 2013 in Essen, Kongressband ISBN-13:9783-932570-68-1, Poster, GtV-Bundesverband Geothermie e.V., 2013.

Seithel, R.: Charakterisierung tektonischer Spannungen für ein Geothermieprojekt in der süddeutschen Molasse. M-3, in: Interne Schriftenreihe Institut für Angewandte Geowissenschaften Fachbereich Geothermie, edited by: Kohl, T., 2013.

Shen, B.: FRACOD Version 1.1, User's manual, Fracom Ltd, 2002.

Shen, B. and Stephansson, O.: Modification of the G-criterion of crack propagation in compression. Int. J. of Engineering Fracture Mechanics, 47, 177-189, 1993a.

Shen, B. and Stephansson, O.: Numerical analysis of Mode I and Mode II propagation of rock fractures, Int. J. Rock Mech. Min., 30, 861-867, 1993b.

Shen, B., Stephansson, O., and Rinne, M.: Modelling Rock Fracturing Processes - A Fracture Mechanics Approach Using FRACOD. ISBN: 978-94-007-6903-8 (Print) 978-94-007-69045 (Online), Springer, Heidelberg, New York, 2014.

Worthoff, R. and Siemes, W.: Grundbegriffe der Verfahrenstechnik, 3. vollständig überarbeitete Auflage, 2012.

Ziefle, G.: Simulation hydromechanischer Effekte in Störungszonen für geothermierelevante Fragestellungen. Der Geothermie Kongress DGK 2013 in Essen, Kongressband ISBN-13:978-3932570-68-1, Forum 4.2, 12 pp., GtV-Bundesverband Geothermie e.V., 2013.

Zoback, M. D.: Reservoir Geomechanics. Cambridge University Press, Cambridge, 2007. 